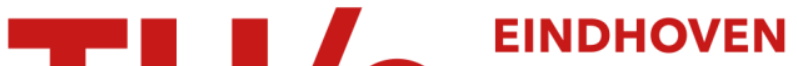 UNIVERSITY OF TECHNOLOGY
}

\section{8-Gb/s RZ-DQPSK transmission with FBG-based in-line dispersion compensation}

\section{Citation for published version (APA):}

Borne, van den, D., Veljanovski, V., Gaubatz, U., Paquet, C., Painchaud, Y., Gottwald, E., Khoe, G. D., \& Waardt, de, H. (2007). 42.8-Gb/s RZ-DQPSK transmission with FBG-based in-line dispersion compensation. IEEE Photonics Technology Letters, 19(14), 1069-1071. https://doi.org/10.1109/LPT.2007.899813

DOI:

10.1109/LPT.2007.899813

Document status and date:

Published: 01/01/2007

\section{Document Version:}

Publisher's PDF, also known as Version of Record (includes final page, issue and volume numbers)

\section{Please check the document version of this publication:}

- A submitted manuscript is the version of the article upon submission and before peer-review. There can be important differences between the submitted version and the official published version of record. People interested in the research are advised to contact the author for the final version of the publication, or visit the $\mathrm{DOI}$ to the publisher's website.

- The final author version and the galley proof are versions of the publication after peer review.

- The final published version features the final layout of the paper including the volume, issue and page numbers.

Link to publication

\section{General rights}

Copyright and moral rights for the publications made accessible in the public portal are retained by the authors and/or other copyright owners and it is a condition of accessing publications that users recognise and abide by the legal requirements associated with these rights.

- Users may download and print one copy of any publication from the public portal for the purpose of private study or research.

- You may not further distribute the material or use it for any profit-making activity or commercial gain

- You may freely distribute the URL identifying the publication in the public portal.

If the publication is distributed under the terms of Article 25fa of the Dutch Copyright Act, indicated by the "Taverne" license above, please follow below link for the End User Agreement:

www.tue.nl/taverne

Take down policy

If you believe that this document breaches copyright please contact us at:

openaccess@tue.nl

providing details and we will investigate your claim. 


\title{
42.8-Gb/s RZ-DQPSK Transmission With FBG-Based In-Line Dispersion Compensation
}

\author{
D. van den Borne, Student Member, IEEE, V. Veljanovski, U. Gaubatz, C. Paquet, Y. Painchaud, E. Gottwald, \\ G. D. Khoe, Fellow, IEEE, and H. de Waardt, Member, IEEE
}

\begin{abstract}
Phase ripple impairments induced through cascaded fiber Bragg gratings (FBGs) are discussed for $42.8-\mathrm{Gb} / \mathrm{s}$ transmission. We show the feasibility of transmission over $1140 \mathrm{~km}(12 \times$ $95 \mathrm{~km})$ using return-to-zero differential quadrature phase-shift keying modulation and FBG-only dispersion compensation. We further compare FBGs with dispersion-compensating fiber for dispersion compensation and analyze the influence of wavelength detuning.
\end{abstract}

Index Terms-Differential quadrature phase-shift keying (DQPSK), dispersion compensation, fiber Bragg gratings (FBGs), optical communication, phase ripple (PR).

\section{INTRODUCTION}

D ISPERSION-COMPENSATING fiber (DCF) is currently used as the standard solution for group-velocity-dispersion (GVD) compensation in long-haul transmission links, since it yields colorless, slope-matched dispersion cancellation with negligible cascading impairments. However, DCF is limited in optical input power to avoid nonlinear impairments and has a relatively high insertion loss, which complicates link design.

Among the promising developments towards more cost-effective optical transmission systems are chirped multichannel fiber Bragg gratings (FBGs) for in-line dispersion compensation. Chirped FBGs have a negligible nonlinearity and low insertion loss [1], [2]. This potentially allows simpler, more cost-effective, erbium-doped fiber amplifier (EDFA) design by placing the FBG between the EDFA output and transmission fiber, omitting the need for interstage access. The main drawback of FBGs is that they suffer from distortions in their phase response, better known as group delay ripple (GDR) [3]. Fig. 1(b) depicts as an example the GDR of a typical FBG channel. The GDR is caused by imperfections in the gratings fabrication process. Improved fabrication processes have, however, gradually reduced the GDR of state-of-the-art slope-matched FBGs [4], such that for 10.7-Gb/s transmission FBG-based in-line dispersion compensation is an appealing alternative to DCF, up to approximately $2000 \mathrm{~km} \mathrm{[5].}$

Manuscript received January 30, 2007; revised April 12, 2007.

D. van den Borne, G. D. Khoe, and H. de Waardt are with the COBRA Institute, Eindhoven University of Technology, 5600 MB Eindhoven, The Netherlands (e-mail: d.v.d.borne@tue.nl)

V. Veljanovski is with Siemens PSE, D-81359 Munich, Germany.

U. Gaubatz and E. Gottwald are with Nokia Siemens Networks GmbH \& Co. KG, D-81359, Munich, Germany.

C. Paquet and Y. Painchaud are with TeraXion Inc., Quebec City, Quebec G1P 4S8, Canada.

Color versions of one or more of the figures in this letter are available online at http://ieeexplore.ieee.org.

Digital Object Identifier 10.1109/LPT.2007.899813
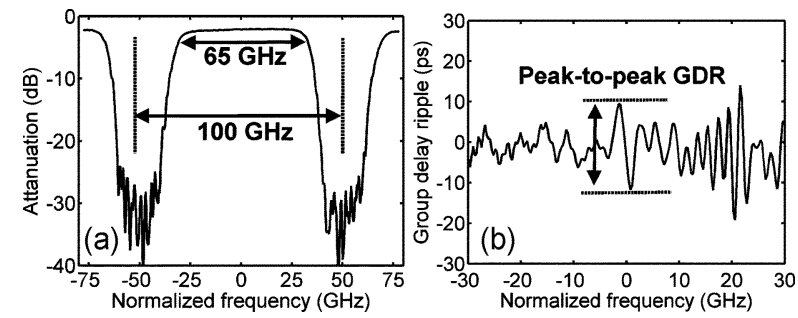

Fig. 1. (a) Amplitude response and (b) GDR of a typical FBG channel.

For future link upgrades (e.g., from 10.7 to $42.8 \mathrm{~Gb} / \mathrm{s}$ per wavelength-division-multiplexing (WDM) channel), the FBGinduced penalty can still be a key concern since the higher line rate increases the associated penalty [6]. The FBG peak-to-peak ripple amplitude is a much larger fraction of the bit period for $42.8-\mathrm{Gb} / \mathrm{s}$ modulated signals in comparison to $10.7-\mathrm{Gb} / \mathrm{s}$ modulation. The ripple period on the other hand is usually well below the modulation frequency for $42.8-\mathrm{Gb} / \mathrm{s}$ modulated signals, which reduces the ripple impact [3]. Note that the best prediction of the penalty associated with cascaded FBGs is generally the phase ripple (PR) weighted by the signal spectrum [7]. For FBGs that have a channelized dispersion-compensation profile, as discussed here [see Fig. 1(a)], the broad optical spectrum can further increase the penalty because the FBGs incur narrowband filtering and have an increased PR near the edge of the passband. It is, therefore, advantageous to use a $42.8-\mathrm{Gb} / \mathrm{s}$ modulation format with a relatively narrow optical spectrum and longer bit period (in comparison to binary modulation formats), as for example return-to-zero differential quadrature phase-shift keying (RZ-DQPSK). The PR penalty is generally also smaller for phase modulated formats in comparison to amplitude modulation [8].

In this letter, we discuss the PR-induced penalties on longhaul 42.8-Gb/s transmission when FBGs are used for in-line dispersion compensation. We show that in combination with RZ-DQPSK modulation, a 1140-km transmission distance is feasible.

\section{EXPERIMENTAL SETUP}

Fig. 2 depicts the recirculating loop setup. In this experiment, 32 distributed feedback laser outputs are combined on a 100-GHz ITU grid, from 1538.2 to $1563.0 \mathrm{~nm}$. A 100-GHz channel grid is used here throughout the experiments because the channelized FBGs have a 100-GHz periodicity [Fig. 1(a)]. The RZ-DQPSK modulator chain starts with a Mach-Zehnder modulator (MZM), carving a pulse with a 50\% duty cycle. The second modulator is an integrated DQPSK modulator [9]. A 21.4-Gb/s pseudorandom bit sequence with a length of $2^{15}-1$ is split in two and fed to both inputs of the $42.8-\mathrm{Gb} / \mathrm{s} \mathrm{DQPSK}$ 


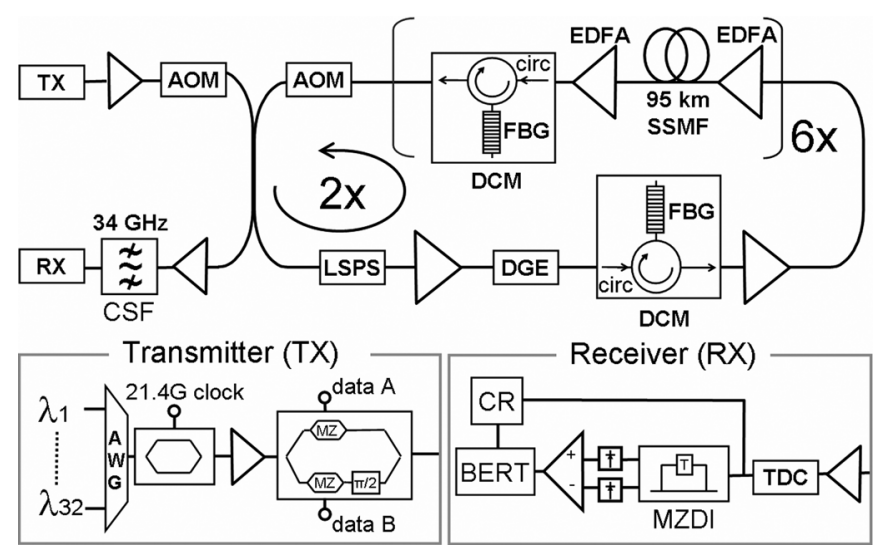

Fig. 2. Experimental setup. Circ: circulator. AOM: acoustic optical modulator.

modulator, with the second sequence being inverted and delayed over 10 bits for decorrelation.

The recirculating loop used in the transmission experiment consist of $6 \times 95 \mathrm{~km}$ standard single-mode fiber (SSMF) spans. The average loss of the SSMF spans is $19.0 \mathrm{~dB}$. EDFA-only amplification is used, with double-stage EDFAs to control the tilt of the WDM spectrum. The SSMF input power is $\sim 0.5 \mathrm{dBm}$ per WDM channel. Before the first span, an FBG-based dispersion-compensation module (DCM) with $-1020 \mathrm{ps} / \mathrm{nm}$ of GVD (at $1550 \mathrm{~nm}$ ) is used for precompensation, creating a double periodic dispersion map. The launch power into the DCF-based DCMs is $\sim 7 \mathrm{~dB}$ reduced with respect to the SSMF launch power. Loop-induced polarization effects are reduced using a loop-synchronous polarization scrambler and power equalization of the dense WDM channels is provided by a channelized dynamic gain equalizer (DGE).

At the receiver, the desired WDM channel is selected using a narrowband 34-GHz channel-selection filter (CSF) and the residual GVD is per-channel optimized with a tunable dispersion compensator (DCF/SSMF-based) to minimize the bit-error rate (BER). After the CSF, the signal is split and one part is used for clock recovery. The other part is fed to a two-bit (94 ps) Mach-Zehnder delay interferometer (MZDI) to convert the signal from phase to intensity modulation, followed by a balanced detector. The use of a two-bit instead of a one-bit delay MZDI might result in slightly higher penalties [11]. The signal is demultiplexed to $10.7 \mathrm{~Gb} / \mathrm{s}$ with a $1: 2$ demultiplexer and evaluated using a BER tester programmed for the expected bit sequence.

\section{EXPERIMENTAL RESULTS}

To analyze the impairments resulting from the cascaded FBGs, the performance for all 32 WDM channels is measured after two circulations $(1140 \mathrm{~km})$. First, in-line dispersion compensation with only FBG-based DCMs is considered. The six in-line DCMs in the recirculating loop have either a GVD of $-1345 \mathrm{ps} / \mathrm{nm}(5 \times)$ or $-1681 \mathrm{ps} / \mathrm{nm}(1 \times)$. Hence, after two recirculations, a total number of 14 FBGs is cascaded. Fig. 3(a) depicts the measured $Q$-factor for all WDM channels. The PR penalty is clearly visible through the large $(3.0 \mathrm{~dB})$ spread in performance between the 32 WDM channels. Despite the significant PR-induced penalty, the measured $Q$-factor is for all channels above the forward-error-correction (FEC) limit of concatenated FEC code with $7 \%$ overhead $(9.0 \mathrm{~dB})$.
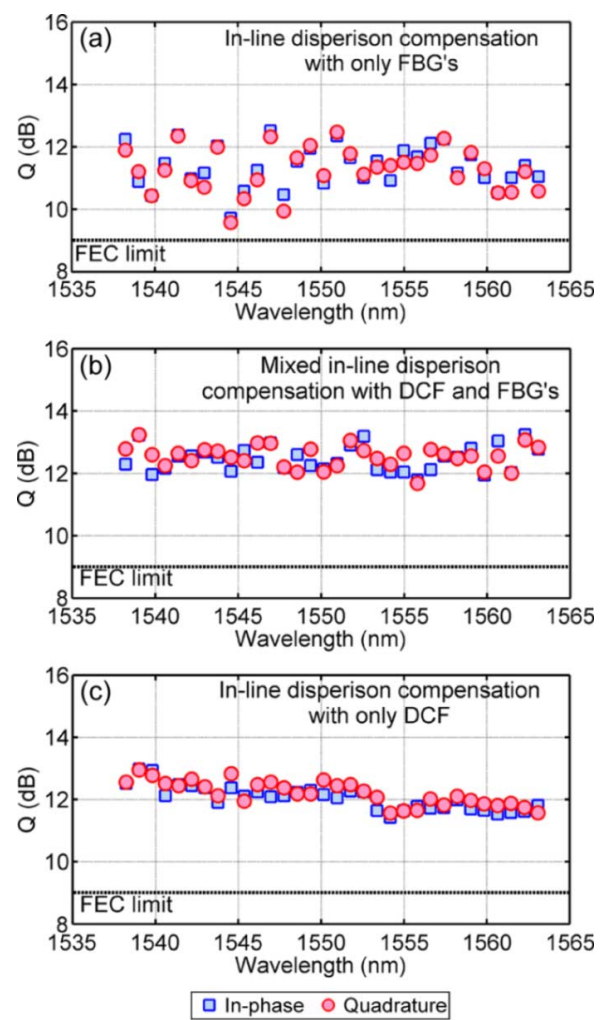

Fig. 3. Measured $Q$-factor for $32 \mathrm{WDM}$ channels after $1140 \mathrm{~km}(12 \times 95 \mathrm{~km})$ of SSMF using dispersion compensation with (a) only FBGs, (b) mixed DCF and FBGs, and (c) only DCF.

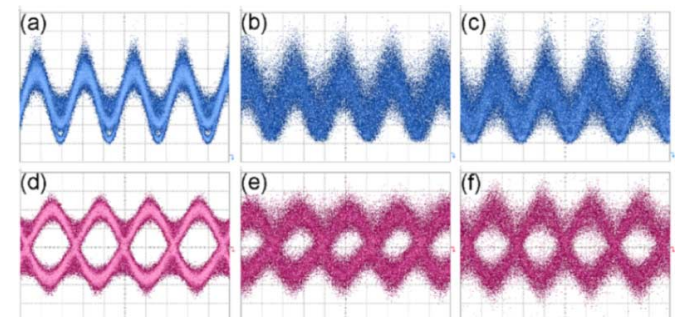

Fig. 4. Eye diagrams showing the signal before phase demodulation [(a)-(c)] and the quadrature tributary after demodulation [(d)-(f)]. Back-to-back [(a), (d)] and after 1140-km transmission for $\lambda=1553.3 \mathrm{~nm}[(\mathrm{~b})$, (e) $]$ and $\lambda=$ $1538.2 \mathrm{~nm}[(\mathrm{c}),(\mathrm{f})]$.

Fig. 4 shows eye diagrams before and after phase demodulation (quadrature tributary). The distortions in the back-toback eye diagram before phase demodulation [Fig. 4(a)] result from narrowband filtering at the receiver. After transmission, the combination of residual dispersion and PR impairments results in a WDM channel dependent eye shape. The eye diagram in Fig. 4(e) shows a more severe PR penalty $(Q$-factor $11.2 \mathrm{~dB})$ than the eye diagram in Fig. 4(f) $(Q$-factor $12.3 \mathrm{~dB})$. Note that in the experiment the residual dispersion is optimized on a per-channel basis to minimize the BER. The measured difference in optimal postcompensation between the channels shown in Fig. 4(e) and (f) is approximately 220 ps/nm. This indicates that optimizing the residual dispersion can be used to reduce the PR associated penalty [8], [10]. In deployed systems, this would require per-channel tunable dispersion compensation at the receiver, for example, through the use of a thermally tuned 

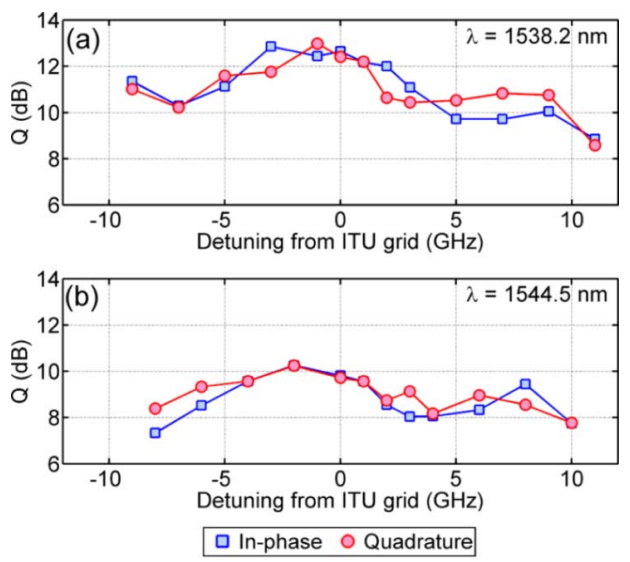

Fig. 5. Measured $Q$-factor versus wavelength detuning from the ITU grid after $1140 \mathrm{~km}$, for the WDM channels at (a) 1538.2 and (b) $1544.5 \mathrm{~nm}$.

FBG [6]. In the absence of PR impairments, the residual dispersion would normally be close to zero [9].

Next, every second FBG-based DCMs is replaced with DCF-based DCMs and the measured performance for all WDM channels is depicted in Fig. 3(b). The in-line dispersion compensation now consist of FBG-DCMs $(-1345 \mathrm{ps} / \mathrm{nm}, 3 \times)$ and DCF $(-1512 \mathrm{ps} / \mathrm{nm}, 3 \times)$. The smaller number of cascaded FBG clearly improves the transmission performance. The spread between the WDM channels is reduced to $1.5 \mathrm{~dB}$ and the average $Q$-factor is increased to $12.5 \mathrm{~dB}$, resulting in nearly a 3-dB margin with respect to the FEC limit.

Finally, Fig. 3(c) shows the measured performance when all FBG-DCMs are replaced by DCF except for the precompensation DCM. The in-line dispersion map consists now of DCF modules with either $-1345 \mathrm{ps} / \mathrm{nm}(3 \times)$ or $-1512 \mathrm{ps} / \mathrm{nm}(3 \times)$ of GVD. The average $Q$-factor is with $12.1 \mathrm{~dB}$ slightly lower in comparison to the mixed FBG/DCF in-line dispersion compensation. The measured $Q$-factor shows a performance difference between the lower and higher part of the WDM spectrum. We conjecture that this is the result of increased nonlinear impairments in the DCF due to a tilt in the WDM spectrum, which increases the power in the higher part of the WDM spectrum. This illustrates that FBG-based inline dispersion compensation can simplify EDFA spectral tilt control. The spread between adjacent WDM channels is reduced to approximately $1 \mathrm{~dB}$.

\section{WAVELENGTh Detuning}

The performance in Fig. 3 depicts the measured $Q$-factor when the WDM channel is centered on the ITU grid, whereas PR penalties can change significantly with only a small change in center wavelength [12]. Fig. 5 depicts the measured $Q$-factor as a function of the wavelength detuning. Note that the channelized DGE used in the recirculating loop has a $42-\mathrm{GHz} 3-\mathrm{dB}$ bandwidth and the detuning range is, thus, not limited by the channelized FBGs. To measure the penalty as a function of wavelength detuning, both the wavelength of the transmitter laser and the center wavelength of the receiver-side CSF are changed. Fig. 5(a) shows the measured $Q$-factor for the channel at $1538.2 \mathrm{~nm}$, which suffers only from a small PR penalty, whereas the channel at $1544.5 \mathrm{~nm}$ is severely affected [Fig. 5(b)]. Both channels show, however, that the PR penalty can easily change with up to $3 \mathrm{~dB}$ within a $+/-5-\mathrm{GHz}$ detuning range. Note though that a typical laser wavelength drift over the system lifetime would be $+/-1.5 \mathrm{GHz}$.

As evident from Fig. 5(b), the measured $Q$-factor drops below the FEC limit within the detuning range. The PR-induced penalty is, however, artificially enlarged in these experiments because each of the FBGs is passed twice within the recirculating loop. The peak-to-peak PR increases linearly when the same FBG is passed multiple times, whereas it increases statistically (square-root) when independent FBGs are cascaded, as occurs in field deployment [12]. Hence, the peak-to-peak PR will be $40 \%$ higher for a recirculating loop with two recirculations in comparison to a straight line.

\section{CONCLUSION}

We compared FBG-only, mixed FBG/DCF, and DCF-only in-line dispersion compensation, which shows the potential impact of FBG-based in-line dispersion compensation on 42.8-Gb/s RZ-DQPSK transmission. Long-haul transmission with only FBGs for in-line dispersion compensation might not be feasible considering the small margins available with $42.8-\mathrm{Gb} / \mathrm{s}$ transmission. However, a smaller number of FBGs (up to $\sim 10$ ) result in an acceptable PR-related penalty, which is comparable to or smaller than the increased nonlinear penalty when DCF is used for in-line dispersion compensation. However, tunable dispersion compensation at the receiver is desirable to reduce the impact of PR impairments.

\section{REFERENCES}

[1] K. O. Hill and G. Meltz, "Fiber Bragg grating technology fundamentals and overview," J. Lightw. Technol., vol. 15, no. 8, pp. 1263-1276, Aug. 1997.

[2] H. S. Fews, M. F. Stephens, and A. Straw et al., "Experimental comparison of fibre and grating-based dispersion compensation schemes for 40 channel 10 Gb/s DWDM systems," in Proc. ECOC 2006, Cannes, France, Paper Th3.2.5.

[3] C. Scheerer, C. Glingener, and G. Fischer et al., "Influence of filter group delay ripples on system performance," in Proc. ECOC 1999, Nice, France, p. I-410.

[4] Y. Painchaud, C. Paquet, and M. Poulin et al., "Low-penalty cascade of low-ripple FBG-based dispersion compensators," in Proc. ECOC 2006, Cannes, France, Paper Th4.2.7.

[5] D. van den Borne, V. Veljanovski, and E. de Man et al., "Cost-effective 10.7-Gbit/s long-haul transmission using fiber Bragg gratings for in-line dispersion compensation," in Proc. OFC 2007, Anaheim, CA, Paper OThS5.

[6] H. Bissessur, C. Bastide, and A. Hugbart, "Performance characterization of components with phase ripple for different $40 \mathrm{~Gb} / \mathrm{s}$ formats," in Proc. OFC 2006, Anaheim, CA, Paper OFN4.

[7] X. Fan, D. Labrake, and J. Brennan, "Chirped fiber gratings characterization with phase ripples," in Proc. OFC 2003, Atlanta, GA, Paper FC2.

[8] X. Liu, L. F. Mollennauer, and X. Wei, "Impact of group-delay ripple in transmission systems including phase-modulated formats," IEEE Photon. Technol. Lett., vol. 16, no. 1, pp. 305-307, Jan. 2004.

[9] D. van den Borne, S. L. Jansen, and G. D. Khoe et al., "Line optimization in long-haul transmission systems with 42.8-Gbit/s RZ-DQPSK modulation," in Proc. OFC 2006, Anaheim, CA, Paper OFD2.

[10] N. Cheng and J. C. Carterledge, "Effect of residual dispersion and phase response ripple at $40 \mathrm{~Gb} / \mathrm{s}$ using a tunable chirped fiber Bragg grating," in Proc. OFC 2006, Anaheim, CA, Paper OWI46.

[11] Y. Lize, L. Christen, and P. Saghari et al., "Implication of chromatic dispersion on frequency offset and bit delay mismatch penalty in DPSK demodulation," in Proc. ECOC 2006, Cannes, France, Paper 3.2.5.

[12] M. H. Eiselt, C. B. Clausen, and R. W. Tkach, "Performance characterization of components with group delay fluctuations," IEEE Photon Technol. Lett., vol. 15, no. 8, pp. 1076-1078, Aug. 2003. 